American Journal of Applied Sciences 1 (4): 321-326, 2004

ISSN 1546-9239

(C) Science Publications, 2004

\title{
Potential of Rice Husk and Rice Husk Ash for Phenol Removal in Aqueous Systems
}

\author{
${ }^{1}$ Mahvi, A. H., ${ }^{2}$ A. Maleki and ${ }^{3}$ A. Eslami \\ ${ }^{1}$ Department of Environmental Health Engineering, Center for \\ Environmental Research Tehran University of Medical Sciences, Tehran, Iran \\ ${ }^{2}$ Department Environmental Health Engineering \\ Kordestan University of Medical Sciences, Sanandaj, Iran \\ ${ }^{3}$ Department of Environmental Health, Faculty of Health \\ Zanjan University of Medical Sciences, Zanjan, Iran
}

\begin{abstract}
The potential of rice husk and rice husk ash for phenol adsorption from aqueous solution was studied. Batch kinetics and isotherm studies were carried out under varying experimental conditions of contact time, phenol concentration, adsorbent dose and $\mathrm{pH}$. Adsorption equilibrium of rice husk and rice husk ash was reached within 6 hours for phenolic concentration 150-500 $\mu \mathrm{g} / \mathrm{L}$ and 3 hours for phenol concentration 500-1300 $\mu \mathrm{g} / \mathrm{L}$, respectively. Kinetics of adsorption obeyed a firstorder rate equation. The adsorption of phenol increases with increasing the solution $\mathrm{pH}$ value. The suitability of the Freundlich and Langmuir adsorption models of the equilibrium data was investigated for each phenol-sorbent system. The results showed that the equilibrium data for all the phenol-sorbent systems fitted the Freundlich model best within the concentration range studied. A comparative study showed that rice husk ash is very effective than rice husk for phenol removal. The studies showed that the rice husk ash can be used as an efficient adsorbent material for removal of phenolic from water and wastewater.
\end{abstract}

Key words: Phenol, Rice Husk, Rice Husk Ash, Adsorption, Aqueous System

\section{INTRODUCTION}

There is growing concern about widespread contamination of surface and ground water by various organic compounds due to the rapid development of chemical and petrol chemical industries over the past several decades. So, many industrial wastes contain organics which are difficult, or impossible to remove conventional biological treatment processes ${ }^{[1]}$. In the past several decades, extensive research has been conducted to develop innovative and promising adsorbent material for dealing with the treatment problem of contaminate industrial effluents. The ultimate goal of this endeavor is to identify an effective and expensive adsorbent for the Volatile Organic Compound (VOC) removal from aqueous solution ${ }^{[2]}$.

Phenols as a class of organics are similar in structure the more common herbicides and insecticides in that they are resistant to biodegration. Phenol is very soluble in water. The odor threshold for phenol is $0.04 \mathrm{ppm}$ (U.S.EPA). Their presence in water supplies is noticed as had taste and odor ${ }^{[3]}$. In the presence of chlorine in drinking water, phenols form chlorophenol, which has a medicinal taste, which is quite pronounced and objectionable $\mathrm{e}^{[4,5]}$. Phenols are considered as priority pollutants since they are harmful to organisms at low concentrations and many of them have been classified as hazardous pollutants because of their potential harm to human health. Stringent US Environmental Protection
Agency (EPA) regulation call for lowering phenol content in the wastewater less than $1 \mathrm{mg} / \mathrm{L}^{[6]}$.

There are many methods such as oxidation, precipitation, ion change, solvent extraction and adsorption for removing phenols and its derivatives from aqueous solution ${ }^{[4,7]}$.

Adsorption is a well-established and powerful technique for treating domestic and industrial effluents. However, in water treatment the most widely used methods are adsorbed onto the surface of activated carbon $^{[8,9]}$. Activated carbons remove many of the impurities occurring in water and wastewater ${ }^{[9-11]}$. In spite of these characteristics, because of the high cost and variable performance of carbon regeneration, single use materials are desirable ${ }^{[4,12]}$. This has led many workers to search for more economic, practical and efficient techniques. Bottom ash, brick-kiln ash, fly ash, peat, soil, rice husk, wood, sawdust, bagasse and carbonized bark are some new adsorbent used for organic pollutants, ${ }^{[4,5,7,12-14]}$.

In the search for new and low cost agricultural wastes as source material for widely uses. Rice husk is an agricultural waste produced as byproducts of the rice milling industry to be about more than 100 million tonnes, $96 \%$ of which is generated in developing countries. The utilization of this source of biomass would solve both a disposal problem and also access to cheaper material for adsorption in water pollution control system ${ }^{[15]}$. Since, the main components of rice 
husk are carbon and silica $(15-22 \% \mathrm{SiO} 2$ in hydrated amorphous form like silica gel), it has the potential to be used as an adsorbent ${ }^{[16,17]}$. When rice husk is burnt, about $20 \mathrm{wt} \%$ of the husk remains as ash. The rice husk ash has more than $95 \mathrm{wt} \%$ of silica with high porosity and large surface area, because it retains the skeleton of cellular structure. These properties of the rice husk ash could be used to synthesize siliceous raw materials such as clay materials ${ }^{[7,18]}$. The aim of this study was to explore the possibility using rice husk and rice husk ash for removing phenol from aqueous solution. The influences of various factors, such as initial $\mathrm{pH}$ and initial pollutant concentrations on the sorption capacity were also studied. The Freundlich and Langmuir models were used to analyze the adsorption equilibrium.

\section{MATERIALS AND METHODS}

Preparation of Sorbent: The rice husks used were obtained from the northern part of Iran. The proximate and ultimate analysis of rice husks are shown in Table $1^{[15-17]}$. The rice husk was crushed and sieved with a $30-$ mesh sieve. Then, the husks were thoroughly washed distilled water to remove all dirt and were dried at $100^{\circ} \mathrm{C}$ till constant weight. The dried husks were stored in desiccator until used. The rice husk ash obtained from burning of rice husk in electric oven at $400^{\circ} \mathrm{C}$ for 3 hours. The rice husk ash was sieved with an 80-mesh sieve and stored in a desiccator until used. Typical chemical composition of the mineral ash is: $96.34 \%$ $\mathrm{SiO} 2,2.31 \% \mathrm{~K} 2 \mathrm{O}, 0.45 \% \mathrm{MgO}, 0.41 \% \mathrm{Al} 2 \mathrm{O} 3,0.41 \%$ $\mathrm{CaO}$ and $0.2 \% \mathrm{Fe} 2 \mathrm{O} 3$. Physical and chemical properties of rice husk ash heated at $400^{\circ} \mathrm{C}$ are: $1.88 \%$ carbon, $79.27 \%$ silicon dioxide. The rice husk ash has a BET surface area of $50.14 \mathrm{~m}^{2} / \mathrm{g}$, total pore volume of $0.182 \mathrm{ml} / \mathrm{g}$ and average pore diameter of $14.49 \mathrm{~nm}^{[17]}$.

Chemicals: The test solutions were prepared by diluting of stock solution of phenol to the desired concentrations. A stock solution was obtained by dissolving $1.0 \mathrm{~g}$ of phenol, (obtained from Merek), in cooled distilled water and dilute to $1000 \mathrm{ml}$. The intermediate phenol solution was obtained by dissolving $100 \mathrm{ml}$ of stock solution of phenol in distilled water and dilute to $1000 \mathrm{ml}$ and finally, a standard phenol solution prepared by dissolving $100 \mathrm{ml}$ intermediate phenol solution in distilled water and dilute to $1000 \mathrm{ml}$. The range in concentrations of phenol prepared from standard solution varied between $100 \mu \mathrm{g} / \mathrm{L}$ to $1300 \mu \mathrm{g} / \mathrm{L}$. Before mixing the adsorbent, the $\mathrm{pH}$ of each test solution was adjusted to the required value with diluted and concentrated $\mathrm{H} 2 \mathrm{SO} 4$ and $\mathrm{NaOH}$ solution, respectively. All $\mathrm{pH}$ measurements were carried out with a $\mathrm{pH}$ meter model E520, Metrohm Herisan.

Absorption studies: Sorption studies were conducted in a routine manner by the batch technique.
Table 1: Properties of the Rice Husks

\begin{tabular}{llllll}
\hline $\begin{array}{l}\text { Proximate analysis } \\
\text { (wt \%) }\end{array}$ & $\begin{array}{l}\text { Ultimate analysis } \\
\text { (wt \%) }\end{array}$ & \multicolumn{2}{l}{$\begin{array}{l}\text { Component analysis } \\
\text { (wt \%) }\end{array}$} \\
\hline Volatiles & 59.5 & Carbon & 44.6 & Cellulose & 34.4 \\
Moisture & 7.9 & Hydrogen & 5.6 & Hemi cellulose & 29.3 \\
Ash & 17.1 & Oxygen & 49.3 & Lignin & 19.2 \\
\hline
\end{tabular}

Each phenol solution was placed in $250 \mathrm{ml}$ beakers and a known amount of rice husk ( 1 to $7 \mathrm{~g}$ ), and rice husk ash $(0.1$ to $0.5 \mathrm{~g})$ was added to each beaker. The flasks were agitated on a shaker at a100 rpm constant shaking rate for $6 \mathrm{hr}$ to ensure equilibrium was reached. For the studies with the rice husk, before analysis, samples were detailed by distillation apparatus according to standard methods ${ }^{[19]}$. Then, detailed samples analyzed for the remaining phenol. The studies were performed at a constant temperature of $25^{\circ} \mathrm{C}$ to be representative of environmentally relevant condition. For the studies with the rice husk ash, before analysis, samples were centrifuged at $5000 \mathrm{rpm}$ for $5 \mathrm{~min}$. And the supernatant fluid analyzed for the remaining phenol. Kinetic experiments were conducted using a know weight of adsorbent dosage and employing phenol concentration. Finally the suitability of the Freundlich and Langmuir adsorption model of the equilibrium data was investigated for phenol-sorbent system. All the experiments were carried out in duplicates and the average value were used for further calculations.

Analysis of phenol: The concentration of residual phenol in the sorption medium was determined by the direct photometric method. At the end, after the preparation of samples according to the standard methods, the residual phenol concentrations were measured using a spectrophotometer equipment (spectrophotometer DR-2000, HACH). The absorbance of the colored complex of phenol with 4aminoantipyrine was read at $500 \mathrm{~nm}^{[19]}$.

\section{RESULTS AND DISCUSSION}

The adsorption of phenol in aqueous solution on rice husk and its ash were examined by optimizing various physicochemical parameters such as; $\mathrm{pH}$, contact time, and the amount of adsorbent and adsorbate.

Effect of initial pH: The adsorption of phenol from aqueous solution is dependent on the $\mathrm{pH}$ of the solution, which affects the surface charge of the adsorbent, degree of ionization and speciation of the adsorb ate species. The adsorption of phenol by rice husk and its ash were studied at various $\mathrm{pH}$ values ${ }^{[5,7,8,12,20]}$. The results are displayed in Fig. 1. As was expected, the adsorbed amount decreases with increasing the $\mathrm{Ph}$ value. This can be attributed to the depending of phenol ionization on the $\mathrm{pH}$ value. The ionic fraction of phenolate ion $\varphi_{\text {ions }}$ can be calculated from ${ }^{[6]}$ : 


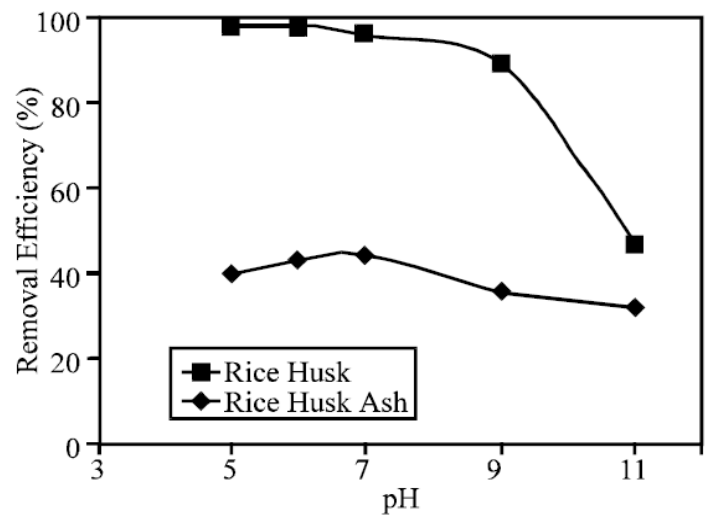

Fig. 1:Effect of $\mathrm{pH}$ on the Removal of Phenol by Rice Husk and Rice Husk Ash (Rice Husk Dosage $=3$ $\mathrm{g} / 100 \mathrm{ml}$, Rice Husk Ash Dosage $=0.5 \mathrm{~g} / 100$ $\mathrm{ml}$, Phenol Concentration $=0.2 \mathrm{mg} / \mathrm{L}$ )

$\varphi_{\text {ions }}=\frac{1}{\left[1+10^{\left(\mathrm{pk}_{\mathrm{a}}-\mathrm{pH}\right)}\right]}$

Obviously, $\varphi_{\text {ions }}$ increases as the $\mathrm{pH}$ value increased. Accordingly, phenol, which is a weak acid $(\mathrm{pKa}=10)$, will be adsorbed to a lesser extent at higher $\mathrm{pH}$ values due to the repulsive force prevailing at higher $\mathrm{pH}$ value $^{[6,16]}$. Also, in the higher $\mathrm{pH}$ range phenol forms salts, which readily ionize leaving negative charge on the phenolic group. At the same time the presence of $\mathrm{OH}^{-}$ions on the adsorbent prevents the uptake of phenolate ions ${ }^{[4,16]}$. Similar behavior has been reported by ${ }^{[8]}$ for the adsorption of phenol by activated carbon, and adsorption of phenol onto bentonite $b y^{[6]} \cdot \mathrm{pH}$ also affects the surface properties of the sorbent, i.e., surface charge of the cells used as sorbent. At very low pH values, the surface of the Sorbent would also be surrounded by the hydronium ions, which enhance the phenol interaction with the binding site of the sorbent by greater attractive forces, hence its uptake on polar adsorbent is reduced ${ }^{[4,7]}$.

Effect of contact time: The adsorption data for the uptake of phenol versus contact time at $150 \mu \mathrm{g} / \mathrm{L}$ initial concentration with $5 \mathrm{~g}$ rice husk and $700 \mu \mathrm{g} / \mathrm{L}$ initial concentration with $0.12 \mathrm{gr}$ rice husk ash were carried out in $\mathrm{pH}$ value of 7 . The results show that the equilibrium time required for the adsorption of phenol on rice husk and its ash are almost $6 \mathrm{hr}$ and $3 \mathrm{hr}$ respectively. These results also indicate that the sorption process can be considered very fast because of the large amount of phenol attached to the sorbent within the first 120min of adsorption. This indicates that rice husk ash would require less residence time for the complete removal of phenol compared to rice husk. Fig. 2 shows the effect of contact time on the removal of phenol by rice husk and its ash. The kinetics of phenol adsorption on both rice husks and its ash follows the first-order rate expression.

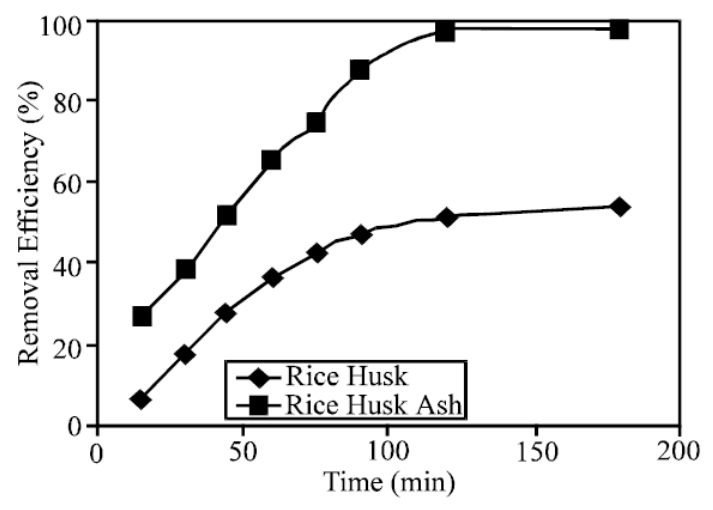

Fig. 2:Effect of Contact Time for the Removal of Phenol by Rice Husk and Rice Husk Ash [(Rice Husk Dosage $=5 \mathrm{~g} / 100 \mathrm{ml}$, Phenol Conc. $=0.15$ $\mathrm{mg} / \mathrm{L}$ ), (Rice Husk Ash Dosage $=0.12 \mathrm{~g} / 100 \mathrm{ml}$, Phenol Conc. $=0.7 \mathrm{mg} / \mathrm{L})]$

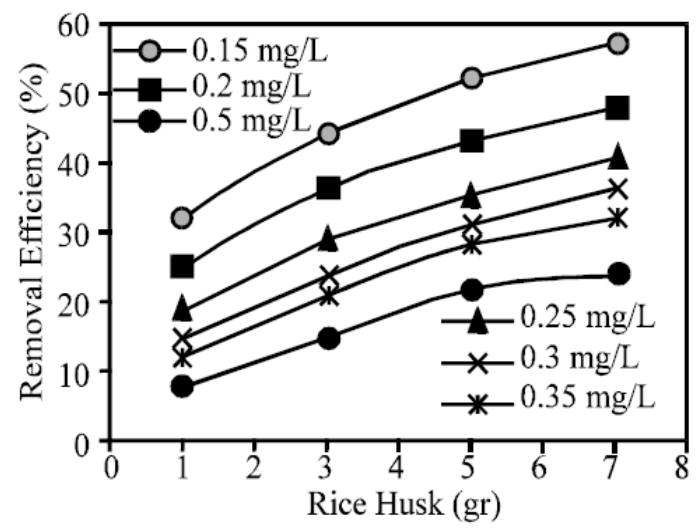

Fig. 3:Effect of Rice Husk on the Removal of Phenol for Various Initial Phenol Concentrations

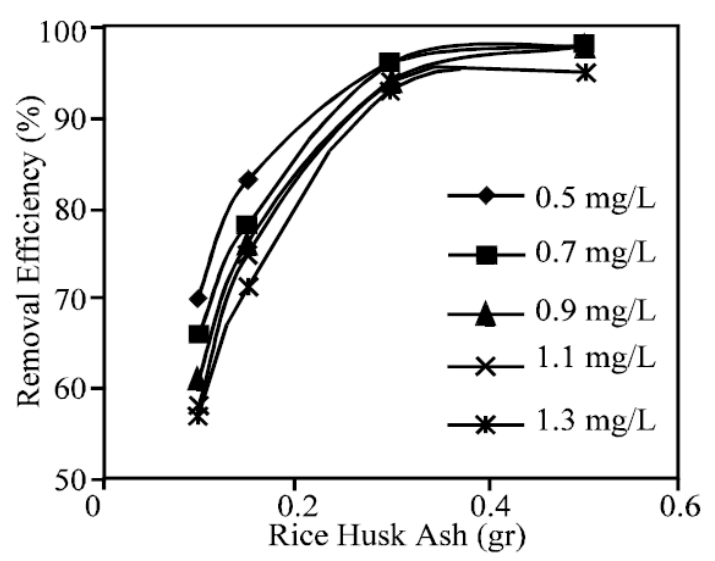

Fig. 4:Effect of Rice Husk Ash on the Removal of Phenol for Various Initial Phenol Concentrations

Effects of adsorbent amount: The amount of adsorbent on the efficiency of adsorption was also studied. Figure 3 and 4 show the removal of phenol by rice husk and its ash at the solution $\mathrm{pH}$ of 7 . 
Table 2: Parameters of Freundlich and Langmuir Isotherm Models

\begin{tabular}{lllllll}
\hline & \multicolumn{2}{l}{ Freundlich constants } & \multicolumn{3}{l}{ Langmuir constants } \\
& $-\mathrm{K}$ & $1 / \mathrm{n}$ & $\mathrm{R}^{2}$ & $\mathrm{Q}^{0}$ & $\mathrm{~b}$ & $\mathrm{R}^{2}$ \\
\hline Rice husk & 0.00092 & 0.195 & 0.96 & 0.0022 & 30.72 & 0.87 \\
Rice husk ash & 0.00092 & 0.57 & 0.98 & 0.886 & 5.15 & 0.97 \\
\hline
\end{tabular}

Adsorbent dosage was varied from $1 \mathrm{~g}$ to $7 \mathrm{~g}$ and $0.1 \mathrm{~g}$ to $0.5 \mathrm{~g}$ for rice husk and its ash, respectively. The results show that for removal of $500 \mu \mathrm{g} / \mathrm{l}$ of phenol in $100 \mathrm{ml}$ of solution, a minimum dosage of $0.3 \mathrm{gr}$ of rice husk ash is required for $96 \%$ removal of phenol.

But, with this condition by rice husk, the removal efficiency is $27 \%$. It is evident that for the quantitative removal of different value of phenol in $100 \mathrm{ml}$ a high dosage of rice husk is required. The data clearly show that the rice husk ash is more effective than rice husk for removal of phenol. The results also clearly indicate that the removal efficiency increases up to the optimum dosage beyond which the removal efficiency is negligible (especially about ash).

Effect of initial phenol concentration: The equilibrium sorption capacities of the sorbents obtained from experimental data at different initial phenol concentration are presented in Fig. 3 and Fig. 4 , and Table 2. As seen from the results, the sorption capacities of the Sorbents increased with increasing phenol concentration while the adsorption yields of phenol showed the opposite trend. When the initial phenol concentration was increased from $150 \mu \mathrm{g} / \mathrm{L}$ to $350 \mu \mathrm{g} / \mathrm{L}$ on rice husk and from $500 \mu \mathrm{g} / \mathrm{L}$ to $1300 \mu \mathrm{g} / \mathrm{L}$ on rice husk ash, the loading capacity increased from $1.56 \times 10^{-6} \mathrm{mg} / \mathrm{mg}$ to $1.96 \times 10^{-6} \mathrm{mg} / \mathrm{mg}$ of rice husk, and from $2.7 \times 10^{-4} \mathrm{mg} / \mathrm{mg}$ to $6.15 \times 10^{-4} \mathrm{mg} / \mathrm{mg}$ of rice husk ash.

Increasing the mass transfer driving force and therefore the rate at which phenol molecules pass from the bulk solution to the particle surface. This would result in higher phenol absorption ${ }^{[20,21]}$. On a relative basis, however, the percentage adsorption of phenol decreases (Fig. 2 and 3) as the initial phenol concentration increases. The equilibrium uptake and adsorption yield were highest for the rice husk ash, which was expected, because of the greater specific surface area and the microporous structure of rice husk ash compared with rice husk.

Adsorption isotherms: Several models have been published in the literature to describe experimental data is of adsorption isotherms. Analysis of the isotherm data is important in order to develop an equation that accurately represents the results and which could be used for design purposes. In this work, both models were used to describe the relationship between the amount of phenol adsorbed and its equilibrium concentration for both rice husks and its ash.

The linear form of the Freundlich isotherm model is given by the following relation ${ }^{[4,6,7,9,10,16]}$ :

$$
\ln \mathrm{q}_{\mathrm{e}}=\ln \mathrm{K}+\frac{1}{\mathrm{n}} \ln \mathrm{C}_{\mathrm{e}}
$$

where, $\mathrm{q}_{\mathrm{e}}$ is the amount adsorbed of equilibrium $(\mathrm{mg} / \mathrm{mg}), \mathrm{C}_{\mathrm{e}}$ is the equilibrium concentration of the adsorbate $(\mathrm{mg} / \mathrm{L})$, and $\mathrm{K}$ and $\frac{1}{\mathrm{n}}$ is the Freundlich constants related to adsorption capacity and adsorption intensity respectively, of the sorbent. The values of $\mathrm{K}$ and $\frac{1}{n}$ can be obtained from the intercept and slope, respectively, of the linear plot of experimental data of $\operatorname{lnq} \mathrm{e}_{\mathrm{e}}$ versus $\operatorname{lnC}_{\mathrm{e}}[4,6,7,9,10,16]$. The linear form of the Langmuir isotherm model can be represented by the following relation ${ }^{[4,6,7,9,10,16]}$ :

$$
\frac{1}{\mathrm{q}_{\mathrm{e}}}=\frac{1}{\mathrm{Q}^{0}}+\frac{1}{\mathrm{bQ}^{0}} \frac{1}{\mathrm{c}_{\mathrm{e}}}
$$

where, $\mathrm{Q}^{0}(\mathrm{mg} / \mathrm{g})$ and $\mathrm{b}(\mathrm{L} / \mathrm{mg})$ are the Langmuir constants related to the maximum adsorption capacity and the energy of adsorption, respectively. These constants can be evaluated from the intercept and slop of the linear plot experimental data of $\frac{1}{q_{e}}$ versus $\frac{1}{C_{e}}{ }^{[4}$, $6,7,9,10,16]$

The linearized Freundlich and Langmuir adsorption isotherms of each sorbet for phenol are shown in Fig. 5 to Fig. 8. The Langmuir and Freundlich constants are displayed in Table 2. The results reveal that the adsorption of phenol on rice husk and its ash obeys the Freundlich adsorption isotherm. But, in general, $R^{2}$ Values, which are a measure of goodness-of-fit (Table 2), show that both the Langmuir and Freundlich isotherm models can adequately describe the adsorption data. The higher value of k, the Freunlich constant, showed easy uptake of phenol from aqueous solution ${ }^{[4,}$ ${ }^{7,8]}$. The adsorption capacity $\mathrm{k}$ is the lowest for the phenol-rice husk system. The $\mathrm{n}$ value, which reflects the intensity of sorption, presents the opposite trend, but as seen from Table 2 for all the sorbents and pollutants, $\mathrm{n}$ values were found high enough for separation. The higher fractional value of $\frac{1}{n}\left(0<\frac{1}{n}<1\right)$ Signifies that the surface of the rice husk is heterogeneous in nature ${ }^{[16]}$. The magnitude of $\mathrm{Q}^{0}$ indicates that the amount of phenol per unit weight of Sorbent to form a complete monolayer on the surface appears to be significantly higher for phenolrice husk ash system in comparison to rice husk. A large value of $b$ also implies that strong bonding of phenolnoccurred with Sorbent ${ }^{[7]}$. Similar observation have been reported of the sorption of phenol on; bentonite, organobentonite and palm seed coat activated carbon, and the sorption of antimony and cadmium on rice husk ${ }^{[2,4,6,16,17,21]}$. 


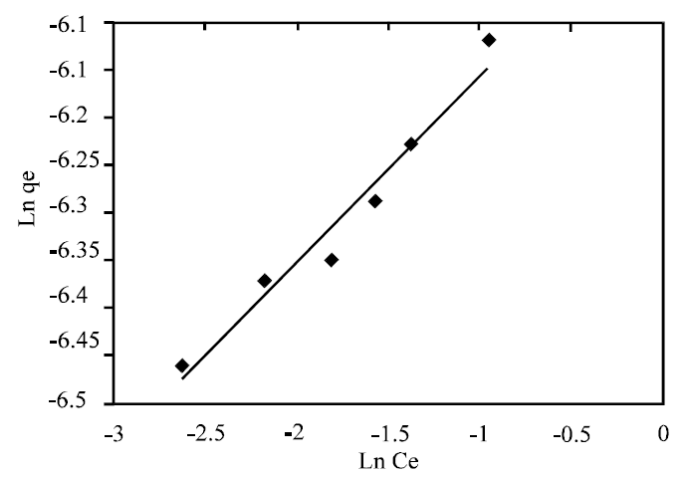

Fig. 5:The Linearized Freundlich Adsorption Isotherm for Phenol with Rice Husk

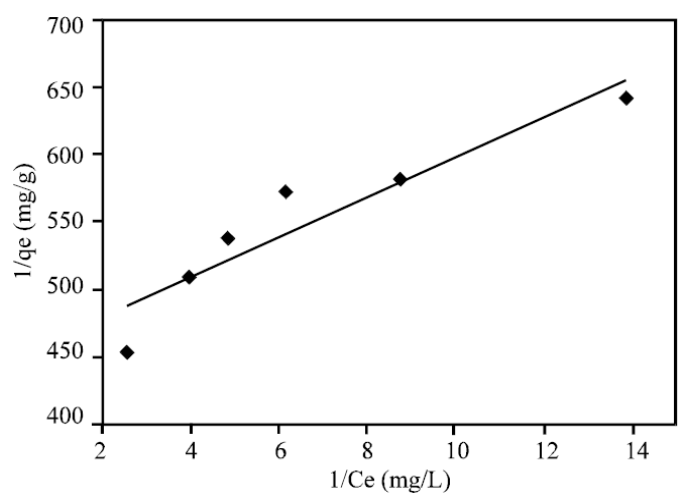

Fig. 6: The Linearized Langmuir Adsorption Isotherm for Phenol with Rice Husk

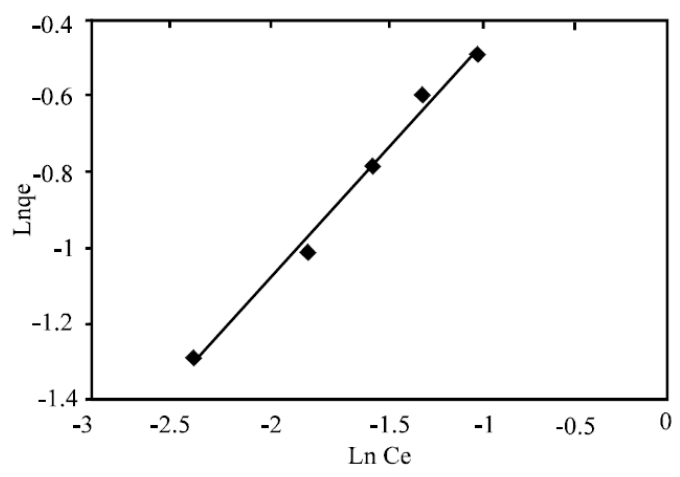

Fig. 7:The Linearized Freundlich Adsorption Isotherm for Phenol with Rice Husk Ash

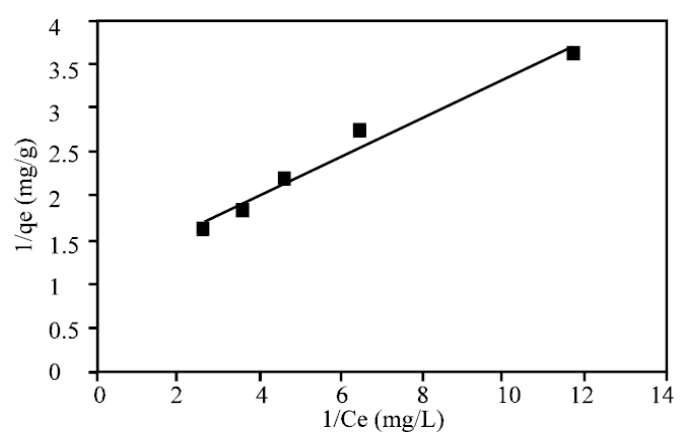

Fig. 8: The Linearized Langmuir Adsorption Isotherm for Phenol with Rice Husk Ash

\section{CONCLUSION}

In this study, the ability of rice husk and rice husk ash to bind phenol was investigated as a function of $\mathrm{pH}$ and initial phenol concentration. Rice husk and rice husk ash adsorption capacity were strongly dependent on the $\mathrm{pH}$ of the solution. The sorption capacity was decreased with an increase in the $\mathrm{pH}$ and an increase in the initial phenol concentration. Although rice husk ash had a higher adsorption capacity $(0.886 \mathrm{mg} / \mathrm{g})$ for phenol, the experimental results indicate that rice husk's ability to adsorb phenol and, consequently, it's possible utilization in the treatment of phenol-contaminated solution, its adsorptive capacity was limited.

Freundlich Langmuir adsorption models expressed the sorption phenomena of phenol to the rice husk and its ash. Consequently, linear regression of the experimental data showed that the Freundlich equation best represented phenol adsorption data. The adsorption of phenol onto both the sorbents follows first-order kinetics. The model parameters would be useful for fabrication and designing of wastewater treatment plants. On the bases of this study, it may be concluded that rice husk and its ash especially, may be used as low-cost, natural and abundant sources for the removal of phenol. They may also be effective in removing other harmful species such as heavy metal ions present in effluents.

\section{ACKNOWLEDGEMENT}

This study was conducted in the Department of Environmental Health Engineering, Tehran University of Medical Sciences. The authors like to thank Mrs. A. Ghasri and Mr. A. Shokati for their assistance in the handling of experiments.

\section{REFERENCES}

1. Crauford, H.B. and G. Cline, 1990. Water treatment plant design. P. 457 New York. American Society of Civil Engineers, American Water Work Association, McGraw Hill.

2. Lin S.H. and M.J. Chery, 2002. Adsorption of phenol \& m-chlorphenol on organobentonites and repeated thermal regeneration. Waste Management, 22: 595-603.

3. Mostafa, M.R., S.E. Sarma and A.M. Yousef, 1989. Removal of organic pollutants from aqueous solution: part1, adsorption of phenol by activated carbon, Indian J. Chem., 28A: 94-8.

4. Rengaraj, S., M. Seuny-Hyeon and R. Sivabalan, 2002. Agricultural solid waste for the removal of organics: adsorption of phenol from water and wastewater by Palm seed coat activated carbon. Waste Management, 22: 543-548. 
5. Street, M., J.W. Patrick and M.J. Camporroperez, 1995. Sorption of phenol and pchlorophenol from water using conventional and novel activated carbons. Water Sci. Res., 29: 467.

6. Banat, F.A., B. Al-Bashir, S. Al-Asheh and O. Hayajneh, 2000. Adsorption of phenol by bentonit. Environmental Pollution, 107: 391-398.

7. Aksu, Z. and J. Yener, 2001. A comparative adsorption/absorption study of Monochlorinated Phenols onto various Sorbent. Waste Management, 21: 695-702.

8. Halouli, Kh.A. and N.M. Drawish, 1995. Effects of $\mathrm{pH}$ and inorganic salts on the adsorption of phenol from aqueous systems on activated decolorizing charcoal. Sep. Sci. Technol., 30: 3313-24.

9. Reynolds, T.D. and P.A. Richards, 1982. Unit operations and processes in environmental engineering. PWS publishers, California.

10. Benefield, L.D. et al., 1982. Process chemistry for water and wastewater treatment. Prentice- Hall Inc., New Jersey.

11. Sawyer, C.N. and P.L. Mc Carty, 1994. Chemistry for environmental engineering, Tata Mc Graw-Hill. New Delhi.

12. Kummar, S., S.N. Upadhyay and Y.D. Upadhyay, 1987. Removal of phenols by adsorption on fly ash. J. Chem. Technol. Biotechnol., 37: 281.

13. Edgehill, Ru and G.Q. Lu (Max), 1998. Adsorption Characteristics of Carbonized Bark for Phenol Penta Phlorophenol. J. Chem. Technol Biotechnol., 71: 27.
14. Srivastava, S.K., R. Tyagi, N. Pal and D. Mohan, 1997. Process development for removal of substituted phenol by carbonaceous adsorbent obtained from fertilizer waste. J. Environ. Eng., 123: 842 .

15. Williams, P.T. and N. Nugranad, 2000. Comparison of products from the pyrolysis and catalytic of rice husks. Energy, 25: 493-513.

16. Khalid, N., S. Ahmad and A. Toheed, 2000. Ahmad J. Potential of rice husks for antimony removal. Applied Radiation and Isotopes, 52: 3038.

17. Nakbanpote, W. et al., 2000. Preconcentration of gold by rice husk ash. Mineral. Eng., 13: 391- 400.

18. Hayashi, H. and S. Nakashima, 1992. Synthesis of trioctahedral smectite from rice husk ash as agrowaste. Clay Science, 8: 4.

19. APHA, AWWA, WEF., 1995. Standard methods for the examination of water and wastewater. 19th Edn. Washington.

20. Caturla, F., J.M. Martin-Martinez, M. MolinaSabio, F. Rodrignez-Reinoso and R. Torregrosa, 1998. Adsorption of substituted phenols on activated carbon. J. Coll. Interface Sci., 124: 528534.

21. Imagawa, A., R. Seto and Y. Nagaosa, 2000. Adsorption of chlorinated hydrocarbons from air and aqueous solutions by carbonized rice husk. Elsevier Science. 